\title{
Personal Metadiscourse Features on TED Talks by British Speakers
}

\author{
Shanty A.Y.P.S Duwila*, Yeni Probowati \\ Faculty Language and Literature, Universitas Wijaya Putra \\ *Corresponding Author. Email: shantiduwila@uwp.ac.id
}

\begin{abstract}
The present research aims to analyze types and functions of personal metadiscourse used by native speakers (British) during their performance on TED Talks. The study applied Ädel's (2006) taxonomy of personal metadiscourse in academic discourses to capture the occurrences of personal metadiscourse. Personal metadiscourses (I, we, you) are commonly applied in written language. Only a few of them can be found in spoken language. Once there is the spoken one, they are typically performed in monologue setting, such as in classroom, seminar, or lecture environment. Data for this research were taken from 5 videos of TED Talks uploaded on YouTube. This study used a qualitative method to analyze the transcriptions provided on the videos. To identify and count the concordances of each unit of personal metadiscourse, AntConc 3.4.3w 2014 was applied. This study revealed that British speakers employ pronouns "I", "You", and "We" both in metatext and audience interaction. However, not all pronouns can be found in each function In metatext category pronoun "You" is rarely used while pronoun I is mostly used by British speakers in discourse organization for exemplifying. Pronoun "You" and "We" are used in audience interaction category for managing messages. This study contributes to ESL/EFL teachers and students who are learning how to present facts effectively, argue and persuade convincingly, and manage speaker and listener visibility.
\end{abstract}

Keywords: British English, metadiscourse features, personal metadiscourse, pronouns, TED Talks

\section{INTRODUCTION}

English is a global lingua franca in many aspects of life. People around the world learn it either as a second or foreign language. Learning a new language is the same as learning a new culture. There are, however, some crucial issues related to cultural facets when learning English as a Second Language (ESL) or English as a Foreign Language (EFL). We cannot fully master a language unless we understand the culture or in another word, we cannot immerse ourselves in ones' culture prior to we learn their language. Through a language, we are able to recognize their set of values and beliefs. The Sapir-Whorf hypothesis proclaimed the influence of language on thought and perception. This implies that the speakers of different languages think and perceive reality in different ways and that each language has its own world view (Hussein, 2012). It can be noticed from the word choices, phrases, clauses, sentences and utterances they produce. For instance, when we learn English idioms, we can notice that the chunk of words in that idiom reflects the way English people see the world. The idiom "raining cats and dogs" expresses the perfect example of its culture when it contrasted to Indonesian. Besides idioms, learning a culture can be perceived using pronouns. After conducting research about the use of pronouns on 33 Americans and 38 Koreans, Na and Choi (2009) found that participants having collectivist orientation are commonly employ first-person plural possessive while participants who are more individualists prefer to use first-person singular possessive. It indicates that the use of pronouns may affect a bidirectional relationship between cultural orientation and language.

Therefore, in line with the above description, the main objective of this research is to analyze some features of Personal Metadiscourse (PMD), especially the use of persona pronouns, namely: I, we, you, which are produced by English native speakers during their performance on TED Talks. The use of persona pronouns is very important in social interactions. This is because the use of personal pronouns is central to faceto-face interaction. They usually define or reveal interpersonal relationships between or among the individuals involved in interaction (Kuo, 1999). In other 
words, personal pronouns are used to represent specific things including individuals, specifically subjective. The pronoun persona is also used to represent certain things, one of which is cultural identity, including individuals from a society. The present research applies metadiscourse framework proposed by Ädel (2006) to explore interpersonalities. Communication functions cultures carried out by native speakers.

Metadiscourse is considered as the essential part of developing communicative capacity in a language. Metadiscourse (MD) is a discourse about discourse and represents idea that writing, and speaking are more than just the exchange of information. Rather, they involve social acts between writers and readers or speakers and listeners (Hyland, 2005; Dafouz-Milne, 2008). The concept of MD developed in the 1980s with prominent early theoretical contributions. The concept takes an audience-sensitive view of communication, recognizing that the ways expressing ideas will be successful if speakers or writers consider the needs and expectations of interlocutors (Heng \& Tan, 2010; Kopple, 1985). Hyland and Tse (2004) proposed interpersonal model of MD which distinguishes interactive and interactional resources. Further, the field received a considerable boost to its popularity and employed corpus-based study as a new methodological (Ädel, 2006; Hyland, 2005). The present study will anchor in theoretical framework provided by (Ädel, 2006). The taxonomies on metadiscourse markers have been varied. Two main approaches are found in the literature and are referred to as the "interactive" and the "reflexive" approaches. The interactive approach views metadiscourse mainly as a form of interaction between text participants (Hyland \& Mauranen, 2017 as cited in Akbas, Hatipoglu, \& Bayyurt, 2017) while the reflexive approach sees metadiscourse principally as a form of linguistic reflexivity (Salas, 2015). Drawing on the reflexive model, Ädel (2006) makes a distinction between personal and impersonal metadiscourse. Personal metadiscourse expressions make explicit reference to the discourse participants, either by pronouns (personal I, we, you, and their oblique and possessive forms) or nouns (such as the writer, dear reader), whereas impersonal metadiscourse expressions do not make direct reference to the discourse participants.

There has been much research using metadiscourse framework in academic writing. Yet not much research is conducted to explore metadiscourse in spoken language. Correia, Mamede, Baptista, and Eskenazi (2016) built a metaTED corpus, a collection of functionally oriented metadiscourse acts annotated in a crowdsourcing setting for spoken language data. The purpose of the research is to find out functions of metadiscourse from set of TED Talks' transcripts. Adopting a theory of metadiscourse (Ädel, 2006), the result shows that there are set of 16 categories were submitted for annotation on Amazon Mechanical Turk.
Using metadiscourse framework in spoken interlanguage EFL learners, Tashi (2019) compared Turkish EFL learners in their spoken English with the practices of native speakers. This research focused on references to the audience, one of personal metadiscourse oriented of Ädel's taxonomy. This study has found that non-native speakers have a weaker propensity to employ metadiscourse expressions regarding audience interaction in their speech. The latest research of metadiscourse in spoken language was conducted by Molino (2018). The data were taken from six Physical Sciences and Engineering undergraduate lectures held in English by Italian native instructors at a large university in Northern Italy. This research conducted analysis of personal metadiscourse and impersonal metadiscourse marker based on the reflexive model proposed by Ädel (2006). The research proved that metatext function is commonly used in monologic than the other function of personal metadiscourse. For impersonal, discourse label and discourse organization are the recurrent forms. The differences of the previous studies mentioned are laid on the focus and object of the study. First study used corpus of TED transcript, the second one conducted on classroom or lectures setting to analyze metadiscourse both personal and impersonal. And the last one compared the use of metadiscourse between Turkish learners and English native in university field.

Empirically, this research examines types and functions of personal metadiscourse markers used by Native speakers in spoken language. Consequently, the first aim of this research is to identify and describe meta-text and writer-reader (speaker-listener) interaction found in TED Talks transcriptions. As Connor and Traversa (2014) argued that the identification of preferred patterns of one's culture in texts is important as this knowledge can inform teachers and L2 learners about the similarity as well as the difference between L1 and target language.

\section{METHOD}

The present research used documentation technique to collect the data. For the purpose of this study, the data consist of five TED Talks transcriptions, which are delivered by British speakers. The data were collected from www.ted.com. Some important facets became consideration in gathering the data to retain the validity of the finding. The data must have met the following criteria: 1) the speakers must be a native British (biographies of the speakers support these criteria), 2) the duration of the speak around 12-15 minutes.

Technique used for data analysis was a qualitative content analysis. Even though the focus of the present study was qualitative aspect, frequencies of words and linguistic expressions on classification tables would be used to support validity of interpretation. 


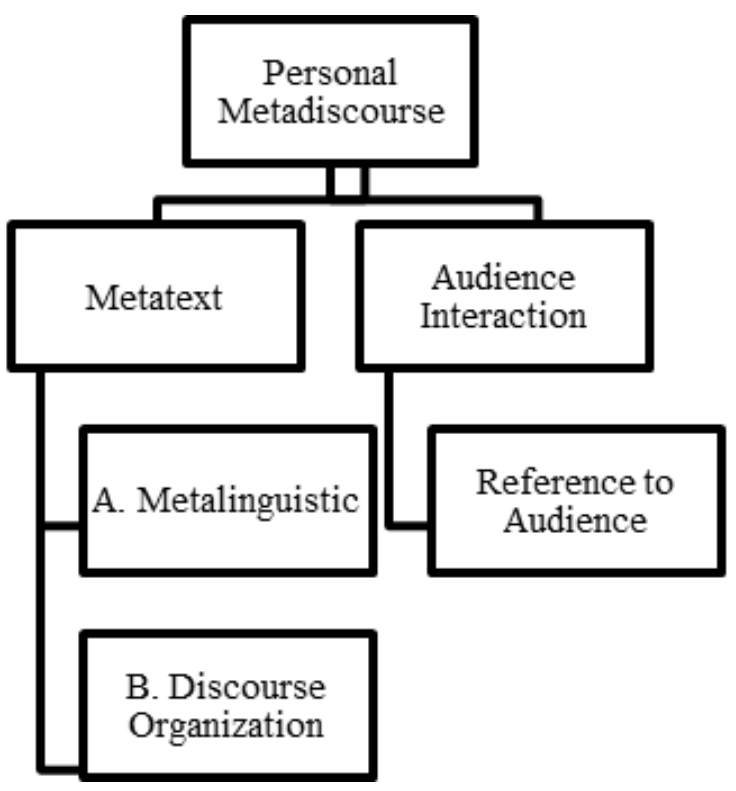

Figure 1 Personal metadiscourse categories and functions.

The analysis was conducted automatically using AntConc 3.4.3 and manually to avoid error. Manual analysis carried out for personal metadiscourse markers in the corpus can be multifunctional. According to Ädel (2006), intervention of human in computer assisted studies is prominent in order to interpret the data within the research context. The selected corpus was analyzed using Ädel's personal metadiscourse model: Metatext and Reader-Writer Oriented (Audience interaction) as in Figure 1.

For the first step, all selected corpus was classified and coded, British speakers (Bs1-5). Bs1 means the first data from the first British speakers. Bs2 means the second data from the second British speakers. The second step was processing the data automatically using AntConc 3.4.3 in order to filter first personal pronouns (focus on first personal pronouns: "I", "You", and "We". Third, deep reading to categorize the pronouns based on the personal metadiscourse markers: metatext and writer-reader interaction (see Table 1). Meta text is defined as aspect of the text itself, such as language use and textual organization. Metadiscourse is categorized as metatext when the writer comments on his/her ongoing discourse, for instance when s/he introduces and closes the topic. Unlike metatext, writer-reader interaction (speaker-audience) focuses on the relationship of writer and reader. In this category, the writer/speaker tries to engage the reader/audience in a mock dialogue, such as anticipate the reader's response and ask questions to the audiences. After classifying the data based on the metadiscursive markers, the results were tabled and interpreted in its context and examining how the various types and subtypes of personal metadiscourse was used and behaved. Finally, these steps lead to the discussion of the intercultural rhetoric.
Table 1. Taxonomy of personal metadiscourse and function in spoken language

\begin{tabular}{lll}
\hline \multicolumn{3}{c}{ Personal Metadiscourse } \\
\hline \multicolumn{1}{c}{ Metatext } & \multicolumn{1}{c}{ Audience Interaction } \\
\hline \multicolumn{1}{c}{ Comments } & \multicolumn{1}{c}{ Organization } & \multicolumn{1}{c}{$\begin{array}{c}\text { Reference to } \\
\text { Audiences }\end{array}$} \\
\hline 1. Repairing & $\begin{array}{l}\text { 1. Introducing } \\
\text { topic }\end{array}$ & $\begin{array}{l}\text { 1. Managing } \\
\text { comprehension/ } \\
\text { channel }\end{array}$ \\
$\begin{array}{lll}\text { 2. } \\
\text { Reformulation }\end{array}$ & $\begin{array}{l}\text { 2. Delimiting } \\
\text { topic }\end{array}$ & $\begin{array}{l}\text { 2. Managing audience } \\
\text { discipline }\end{array}$ \\
$\begin{array}{l}\text { 3. } \\
\text { Commenting } \\
\text { on linguistic } \\
\text { form/ meaning } \\
\text { 4. Clarifying }\end{array}$ & topic & $\begin{array}{l}\text { 3. Anticipating the } \\
\text { audience's response }\end{array}$ \\
$\begin{array}{l}\text { 5. Managing } \\
\text { terminology }\end{array}$ & 5. Enumerating & $\begin{array}{l}\text { 5. Imagining } \\
\text { scenarios }\end{array}$ \\
& 6. Arguing & \\
& 7. Previewing & \\
& 8. Reviewing & \\
& 9. Contextualizing & \\
\hline
\end{tabular}

Note. Adapted from Adel 2010 cited in (Correia et al., 2016)

The following are the explanation of the taxonomy of personal Metadiscourse and function in spoken language as outlined in Table 1. Metalinguistic comments: 1) Repairing means utters suggestions which correct or cancel a preceding contribution, 2) Reformulation means offers an alternative term by added value of expansion because the preceding information was seen not right, 3) Commenting on linguistic form/meaning means referring to linguistic form, word choice and meaning, 4) Clarifying specifies what the addresser saying to avoid misunderstanding, 5) Managing terminology gives definitions to provide terms or labels for phenomena that talked about. Discourse Organization: 1) Introducing topic means opening the topic, 2) Delimiting topic states how the topic is constrained, 3) Concluding topic means closing the topic, Exemplifying means giving example, 5) Enumerating shows how specific parts of the discourse are order in relation to each other, 6) Arguing means stressing the action or against an issue, 7) Previewing points forward in the discourse, 8) Reviewing points backward in the discourse, and 9) Contextualizing comments on the condition of speaking situation and contains traces of the production of the discourse. Reference to Audience: 1) Managing comprehension/channel means refers to the participants' understanding and uptake relation to the channel (on the same page), 2) Managing audience discipline refers to the audience that is addressed, instructed, reprimanded, or complimented, 3) Anticipating the audience's 
response pays special attention to predict the audience's reaction or gives statement of potential objections or counterargument, 4) Managing the message emphasize the core message in what is being conveyed, such provides a big picture, wishes and suggestions for the audience, 5) Imagining scenarios asks the audience to see something from a specific perspective and can be thought of as mutual thought experiment between the addresser and the addressee, taking place in the shared world of discourse rather than in the 'real world'.

\section{FINDINGS AND DISCUSSION}

In line with the concept and qualitative data analysis methods, Table 2 shows the total of word token for each speaker during their performance on TED Talks, and it also presents the total of each pronoun, "I", "You", and "We". To find out accuracy of the total word token and pronouns AntConc 3.4.3 is applied.

Pronoun I is mostly used by the speakers followed by pronouns "You" and "We". It needs to be noticed that not all pronouns are considered personal metadiscourse features. According to Ädel (2006), features of pronouns which relates to the world of discourse, namely within the discourse and during audience interaction will be categorized as personal metadiscourse. In line with this view, Table 3 displays the numbers of personal metadiscourse pronouns as a metatext category.

In this category, the speakers use pronouns related to discourse. When we try to compare Table 2, 3 and 4, we distinguish a big different in numbers of pronouns, for instance, the total number of pronouns I in metatext category is only 108 and in audience interaction is only 26. This numbers explain that during the talk, the speakers not only talk about discourse they also talk about the world. The pronouns cover all functions of metatext. Pronoun I is mostly used during talking about the topic. It is reasonable since in this part the speakers have the audience understand and comprehend the topic they are talking about. The speakers get the audience to engage and take part in the discourse. The speakers argue, give opinion, and exemplify to persuade and convince their audience.

Table 2. Tokens of Pronouns from British Speakers

\begin{tabular}{lccccc}
\hline No & Speakers & I & You & We & $\begin{array}{r}\text { Word } \\
\text { Token }\end{array}$ \\
\hline 1 & BS1 & 72 & 61 & 24 & 2545 \\
2 & BS2 & 56 & 44 & 26 & 1934 \\
3 & BS3 & 84 & 89 & 44 & 2882 \\
4 & BS4 & 187 & 68 & 8 & 2897 \\
5 & BS5 & 25 & 30 & 30 & 2989 \\
\hline
\end{tabular}

\begin{tabular}{|c|c|c|c|}
\hline TOTAL & 292 & 132 & 10.350 \\
\hline \multicolumn{4}{|c|}{$\begin{array}{l}\text { Table 3. Total Tokens of Personal Metadiscourse: } \\
\text { Metatext }\end{array}$} \\
\hline \multicolumn{2}{|l|}{ Personal Metadiscourse } & \multicolumn{2}{|c|}{ Pronouns } \\
\hline Metatext & $\mathrm{I}$ & YOU & WE \\
\hline \multicolumn{4}{|l|}{ Metalinguistic comments } \\
\hline Repairing & 7 & 0 & 1 \\
\hline Reformulation & 6 & 0 & 4 \\
\hline $\begin{array}{l}\text { Commenting on linguistic } \\
\text { form/meaning }\end{array}$ & 8 & 0 & 3 \\
\hline Clarifying & 5 & 6 & 4 \\
\hline Managing terminology & 5 & 0 & 1 \\
\hline \multicolumn{4}{|l|}{ Discourse Organization } \\
\hline Introducing topic & 4 & 0 & 0 \\
\hline Delimiting topic & 4 & 1 & 0 \\
\hline Concluding topic & 6 & 0 & 1 \\
\hline Exemplifying & 54 & 7 & 0 \\
\hline Enumerating & 3 & 3 & 0 \\
\hline Arguing & 0 & 0 & 2 \\
\hline Previewing & 2 & 0 & 0 \\
\hline Reviewing & 1 & 3 & 3 \\
\hline Contextualizing & 3 & 0 & 1 \\
\hline Total & 108 & 20 & 20 \\
\hline
\end{tabular}

Table 4. Personal Metadiscourse: Audience Interaction

\begin{tabular}{lccc}
\hline \multicolumn{1}{c}{ Personal Metadiscourse } & \multicolumn{3}{c}{ Pronouns } \\
\hline \multicolumn{1}{c}{ Audience Interaction } & I & YOU & WE \\
\hline Reference to Audiences & & & \\
Managing comprehension/channel & 6 & 33 & 4 \\
Managing audience discipline & 1 & 6 & 0 \\
Anticipating the audience's response & 5 & 20 & 9 \\
Managing the message & 9 & 33 & 13 \\
Imagining scenarios & 5 & 4 & 4 \\
Total & 26 & 96 & 30 \\
\hline
\end{tabular}

Talking about the world means the discourse does not incompletely related to the present discourse. For example, the speakers give their personal data such as where they graduated from or work at. And even share experience which out of topic in order to raise attention or to lead to the next discourse. Table 5 displays examples of the use of pronoun I which is considered as Non-Metadiscursive pronouns. Table 6 and Table 7 also present some instances from the data which contain non-metadiscursive pronouns: "You" and "We". 
Table 5. Non-Metadiscursive I

\begin{tabular}{ccl}
\hline No & Speakers & \multicolumn{1}{c}{ I } \\
\hline 1 & BS1 & $\begin{array}{l}\text { I graduated from university } \\
\text { I've had the opportunity over the last } \\
\text { couple of days of listening in on } \\
\text { some of your conversations and } \\
\text { watching you interact with each } \\
\text { other. } \\
\text { I'm looking at you. I was sitting here } \\
\text { for five minutes } \\
\text { I need somebody to come up here } \\
\text { and join me on the stage } \\
\ldots \text { B. when I was about eight months } \\
\text { old }\end{array}$ \\
\hline
\end{tabular}

Table 6. Non-Metadiscursive You

\begin{tabular}{|c|c|c|}
\hline No & Speakers & You \\
\hline 1 & BS1 & $\begin{array}{l}\ldots \text { the most assertive person you } \\
\text { know }\end{array}$ \\
\hline 2 & BS2 & But instead of pointing at you... \\
\hline 3 & BS3 & You look really friendly enough \\
\hline 4 & BS4 & $\begin{array}{l}\text { There you go, thank you so much, } \\
\text { you can go, sit back down now. }\end{array}$ \\
\hline 5 & BS5 & $\begin{array}{l}\text {...everyone you love, everyone you } \\
\text { know... }\end{array}$ \\
\hline
\end{tabular}

Considering the findings on Table 3 related to personal metadiscourse in category of metatext, most British speakers prefer using pronouns "I" to "You" and "We". They employ pronoun I to exemplify. During their performance, all speakers tend to start the talk by exemplifying from their own experience. They share their personal experience which is related to the present discourse. Chen, Bell, and Taylor (2016) stated that a 1st-person point of view narrative would have a greater effect than a 3rd-person point of view. It is expected to elevate susceptibility and severity perceptions, leading to persuasion. It is argued that the use of first-person I help to establish a personal connection with the audience. Using a first-person I perspective in spoken content makes an emotional appeal that helps forge a relationship between speaker and audiences. Table 8 presents some instances of language expressions using pronoun I which is the function to exemplify.

Table 7. Non-Metadiscursive We

\begin{tabular}{ccl}
\hline No & Speakers & \multicolumn{1}{c}{ We } \\
\hline 1 & BS1 & $\begin{array}{l}\text { But we have spent the last three years } \\
\text { doing research with academics of } \\
\text { University of Oxford, and most } \\
\text { importantly } \\
\text { We found in some research that they } \\
\text { use more diminutive terms when they } \\
\text { meet somebody } \\
\text { We live in a really visual culture } \\
\text { We can have a little cup of tea } \\
\text { together. } \\
\text { We live in difficult and challenging }\end{array}$ \\
& BS3 & BS5
\end{tabular}

economic times, of course

Considering the findings on Table 3 related to personal metadiscourse in category of metatext, most British speakers prefer using pronouns "I" to "You" and "We". They employ pronoun I to exemplify. During their performance, all speakers tend to start the talk by exemplifying from their own experience. They share their personal experience which is related to the present discourse. Chen, Bell, and Taylor (2016) stated that a 1 st-person point of view narrative would have a greater effect than a 3rd-person point of view. It is expected to elevate susceptibility and severity perceptions, leading to persuasion. It is argued that the use of first-person I help to establish a personal connection with the audience. Using a first-person I perspective in spoken content makes an emotional appeal that helps forge a relationship between speaker and audiences. Table 8 presents some instances of language expressions using pronoun I which is the function to exemplify.

Table 8. Metatext: Exemplifying Using Pronoun I

\begin{tabular}{ccl}
\hline No & Speakers & \multicolumn{1}{c}{ Exemplifying } \\
\hline 1 & BS1 & $\begin{array}{l}\text { I might pick computer programming } \\
\text { as an example for the next decade. } \\
\text { I find, for example, after a period of } \\
\text { pseudo-extroverted behaviour, I need } \\
\text { to repair somewhere on my own. } \\
\text { I knew that it was my big moment as } \\
\text { a rookie voice coach, and I was } \\
\text { going to be able to speak. } \\
\text { Those kind of self-limiting thoughts } \\
\text { like: "I can't do that", "I'm not good } \\
\text { enough", or, "I don't have the time or } \\
\text { the money". } \\
\text { But I think to set the scene, I want to } \\
\text { show } \\
\text { I just wanted to show this picture } \\
\text { because this is remarkable. }\end{array}$ \\
\hline
\end{tabular}

Functions of personal metadiscourse that need to be spotted from Table 3 is arguing. The argumentation function in a discourse is necessary based on the genre of the discourse. Data BS 1-5 that we collected mostly about persuasive narrative discourse purposing audiences to make a change and to be more motivated in life. The arguing function only can be found in Data BS5, which is talking about science. The speaker tries to compare some science theories to strength his argument.

The occurrence of pronoun "You" is higher in audience interaction category than that in metatext category, 1: 4. When using the indefinite version of the pronoun "You", it can be unclear whom the speaker is referring to. It can be used to refer to anyone and/or everyone. The indefinite version of "You" includes the speaker among the referents, even if this is not always the case. If the speaker uses the pronoun "You", it is up to the audience to decide if they view themselves as part of that group or not. The generic "You" can be used to criticize or to share experience by including or excluding them from generalizations. From the present study, the use of pronoun I in audience interaction are for: managing comprehension/channel, managing the 
message, and anticipating the audience's response. Penz (2011) states that there are three basic functions of Meta communicative utterances: metalinguistic referent, metalinguistic operator, and metalinguistic verb. In spoken language, speakers will be a direct informant who will guide audience to their discourse. They will act as communicative as possible. Speakers send a direct contact by asking questions and waiting for the respond in order to proceed in the next discourse. Speakers must also provide some back up plan in case the responses from their audiences beyond their expectation. Table 9 displays the use of pronoun "You" by British speakers in those three functions.

Table 9. Language Expressions of Personal Metadiscourse: Audience Interaction

\begin{tabular}{|c|c|c|}
\hline No & Speakers & Language Expressions \\
\hline 1 & $\begin{array}{l}\text { Managing } \\
\text { Comprehension } \\
\text { /channel }\end{array}$ & $\begin{array}{l}\text { This experiment demonstrates } \\
\text { the power of your mind. The } \\
\text { fact that what is going on up in } \\
\text { your head has such a huge } \\
\text { impact on the actions that you } \\
\text { take, on the decisions you make, } \\
\text { and the things that you } \\
\text { experience. (BS4) }\end{array}$ \\
\hline 2 & $\begin{array}{l}\text { Managing the } \\
\text { Message }\end{array}$ & $\begin{array}{l}\text { You're not necessarily antisocial } \\
\text { you simply realize that you do } \\
\text { better when you have a chance } \\
\text { to lower that level of } \\
\text { stimulation. (BS2) }\end{array}$ \\
\hline 3 & $\begin{array}{l}\text { Anticipating } \\
\text { Audiences' } \\
\text { response }\end{array}$ & $\begin{array}{l}\text { But first, would you like to see } \\
\text { inside the first drawer? How } \\
\text { often do you think about how } \\
\text { yours works? (BS3) }\end{array}$ \\
\hline
\end{tabular}

As it is presented on Table 4, pronoun I is less used and pronoun We employ in managing message. Pronoun We can be used to refer to the speaker and the audiences. It seems that the use of the pronoun We by the speakers is also used to avoid speaking about speaker as an individual, and instead suggest that others are involved, perhaps to lead negative attention away from the speaker in question. By using the pronoun, we, the speaker includes others in the utterance, creating a group with a clear identity, making others responsible for potential issues as well.

\section{CONCLUSION}

Related to the research question, this study has found that the British speakers employ pronouns "I", "You", and "We" in personal metadiscourse categories: metatext and audience interaction. However, not all pronouns can be found in each function. In metatext category pronoun "You" is rarely used. It is reasonable since in this category the speakers lead and guide audiences to understand the discourse. Pronoun $\mathrm{I}$ is mostly used by British speakers in discourse organization for exemplifying. It is necessary to support arguments in a speech by giving examples. And to build a trust or persuade audiences to believe in one's arguments is sharing personal experience which is related to the topics. However, pronoun I does not seem to appear very often in audience interaction. British speakers used pronoun "You" and "We" in managing message for audience interaction. The speakers used pronoun "You" referring to audiences and "We" referring to audiences and the speaker to encourage and suggest them (selves) to do something and to be someone better.

The data used in this present study is very limited. It is alluded more studies to gain an in-depth understanding of personal pronoun metadiscourse, rhetoric, and cultural studies. From the findings and discussion, we can notice metadiscursive markers and functions of pronouns that can benefit for ESL teachers and learners.

\section{ACKNOWLEDGMENTS}

This research was funded by Universitas Wijaya Putra based on Surat Perjanjian Pelaksanaan Penelitian Dosen Pemula Universitas Wijaya Putra Tahun 2020 Nomor: $\quad 025.18 / L P P M-U W P / K-I / V I / 2020 \quad$ June $2^{\text {nd }}$ 2020 .

\section{REFERENCES}

Ädel, A. (2006). Metadiscourse in L1 and L2 English / Annelie Ädel. Studies in Corpus Linguistics, 24, x, $243 \mathrm{p}$.

Akbas, E., Hatipoglu, C., \& Bayyurt, Y. (2017). Mapping out Interactions in Spoken and Written Discourses. Metadiscourse across Genres. Conference Programme \& Book of Abstracts (Cyprus, March 30-April 1, 2017). Online Submission.

Chen, M., Bell, R. A., \& Taylor, L. D. (2017). Persuasive effects of point of view, protagonist competence, and similarity in a health narrative about type 2 diabetes. Journal of Health Communication, 22(8), 702-712.

Connor, U., \& Traversa, A. (2014). The role of intercultural rhetoric in ESP education. 4th CELC Symposium Proceedings: Alternative Pedagogies in the English Language \& Communication Classroom, 19-24.

Correia, R., Mamede, N., Baptista, J., \& Eskenazi, M. (2016). MetaTED: A corpus of metadiscourse for spoken language. Proceedings of the 10th International Conference on Language Resources and Evaluation, LREC 2016, 3907-3913.

Dafouz-Milne, E. (2008). The pragmatic role of textual and interpersonal metadiscourse markers in the construction and attainment of persuasion: A cross- 
linguistic study of newspaper discourse. Journal of Pragmatics, 40(1), 95-113. https://doi.org/10.1016/j.pragma.2007.10.003

Heng, C. S., \& Tan, H. (2010). Extracting and Comparing the Intricacies of Metadiscourse of Two Written Persuasive Corpora. International Journal of Education \& Development Using Information and Communication Technology, 6(3), 124-146.

http://search.ebscohost.com/login.aspx?direct=true $\& \mathrm{db}=$ eue $\& \mathrm{AN}=55305148 \&$ site $=$ ehost live $\&$ scope $=$ site

Hussein, B. A. S. (2012). The sapir-whorf hypothesis today. Theory and Practice in Language Studies, 2(3), 642-646. https://doi.org/10.4304/tpls.2.3.642-646

Hyland, K. (2005). Metadiscourse: Exploring Interaction in Writing. London: Continuum.

Hyland, K., \& Tse, P. (2004). Metadiscourse in Academic Writing: In Applied Linguistics (Vol. 25, Issue 2, pp. 156-177). https://doi.org/10.1093/applin/25.2.156

Kopple, W. J. V. (1985). Some Exploratory Discourse on Metadiscourse. College Composition and Communication, $36(1), \quad 82$. https://doi.org/10.2307/357609

Kuo, C. (1999). The Use of Personal Pronouns: Role Relationships in Scientific Journal Articles. English for Specific Purposes, 18, 121138.
Molino, A. (2018). ? What I'm Speaking Is Almost English...': A Corpus-Based Study of Metadiscourse in English-Medium Lectures at an Italian University. Educational Sciences: Theory and Practice, 18(4), 935-956. https://doi.org/10.12738/estp.2018.4.0330

Na, J., \& Choi, I. (2009). Culture and first-person pronouns. Personality and Social Psychology Bulletin, 35(11), 1492-1499. https://doi.org/10.1177/0146167209343810

Penz, H. (2011). What do we mean by that?'Metadiscourse in ELF Project Discussions. Archibald/Cogo/Jenkins (2011), 185201.

Salas, M. D. (2015). Reflexive metadiscourse in research articles in Spanish: Variation across three disciplines (Linguistics, Economics and Medicine). Journal of Pragmatics, 77, 20-40. https://doi.org/10.1016/j.pragma.2014.12.006

Tashi, T. (2019). Interpersonal Model of Metadiscourse: What is it and Should it be Taught in EFL Writing Classrooms?. Journal of Humanities and Social Sciences Studies, 1(3), 43-48. 